Article

\title{
Study of Antibacterial Properties of Ziziphus mauritiana based Green Synthesized Silver Nanoparticles against Various Bacterial Strains
}

\author{
M. Asimuddin ${ }^{1}$, Mohammed Rafi Shaik ${ }^{2}{ }^{\infty}$, Neeshat Fathima ${ }^{1}$, M. Shaistha Afreen ${ }^{1}$, \\ Syed Farooq Adil ${ }^{2}\left(\mathbb{0}\right.$, Mohammed Rafiq H. Siddiqui ${ }^{2}{ }^{(1)}$, Kaiser Jamil ${ }^{1, *}$ and Mujeeb Khan ${ }^{2, *(1)}$ \\ 1 Center for Biotechnology and Bioinformatics, School of Life Sciences, Jawaharlal Nehru Institute of \\ Advanced Studies (JNIAS), Hyderabad 500003, Telangana, India; mmast7@gmail.com (M.A.); \\ fathimaneeshat17@gmail.com (N.F.); shaisthaafreen2@gmail.com (M.S.A.) \\ 2 Department of Chemistry, College of Science, King Saud University, P.O. 2455, Riyadh 11451, Saudi Arabia; \\ mrshaik@ksu.edu.sa (M.R.S.); sfadil@ksu.edu.sa (S.F.A.); rafiqs@ksu.edu.sa (M.R.H.S.) \\ * Correspondence: kj.bmmrc@gmail.com (K.J.); kmujeeb@ksu.edu.sa (M.K.); Tel.: +966-11-4670439 (M.K.)
}

Received: 27 January 2020; Accepted: 14 February 2020; Published: 17 February 2020

\begin{abstract}
Due to their low cost and environmentally friendly nature, plant extracts based methods have gained significant popularity among researchers for the synthesis of metallic nanoparticles. Herein, green synthesis of silver nanoparticles was performed using the aqueous solution of Ziziphus mauritiana leaves extract (ZM-LE) as a bio-reducing agent. The as-obtained silver nanoparticles were characterized by using UV-Vis spectroscopy, XRD (X-ray diffraction), TEM (transmission electron microscopy), and FT-IR (Fourier-transform infrared spectroscopy). In addition, the effects of the concentrations of the leaves extract, silver nitrate, and the temperature on the preparation of nanoparticles were also investigated. In order to determine the nature of secondary metabolites present in leaves extract, a preliminary investigation of phytoconstituents was carried out using different methods including Folin-Ciocalteu and $\mathrm{AlCl}_{3}$ methods. The results have indicated the presence of a considerable amount of phenolic and flavonoid contents in the leaves extract, which are believed to be responsible for the reduction of silver ions and stabilization of resulting nanoparticles. Indeed, the FT-IR spectrum of silver nanoparticles also confirmed the presence of residual phytomolecules of leaves extract as stabilizing ligands on the surface of nanoparticles. The antibacterial properties of as-obtained silver nanoparticles were tested against various bacterial strains including Escherichia coli, Staphylococcus aureus, Pseudomonas aeruginosa, and Bacillus subtilis. The nanoparticles strongly inhibited the growth of $S$. aureus with a minimum inhibitory concentration (MIC) of $2.5 \mu \mathrm{g} / \mathrm{ml}$ and moderately inhibited the growth of E. coli with a MIC of $5 \mu \mathrm{g} / \mathrm{ml}$.
\end{abstract}

Keywords: Ziziphus mauritiana; green synthesis; plant extracts; silver NPs; biological activity

\section{Introduction}

Synthesis of metallic nanoparticles (NPs) is an area of active research as a result of their advance and fascinating accomplishments in several fields, including biomedical and engineering [1,2]. So far, due to their exciting properties, metal NPs have been successfully applied in drug delivery, imaging, bio-sensing, catalysis, etc. [3] Among various metallic NPs, silver (Ag) NPs have been widely applied for various biomedical purposes due to their remarkable biological properties [4-6]. For instance, the exceptional antimicrobial properties of Ag NPs have been exploited to develop a number of antimicrobial medical products, including wound dressings, surgical instruments, and contraceptive devices, etc. [7-9]. In many cases, the size and shape of NPs plays a crucial role in enhancing the 
properties of Ag NPs. Generally, homogeneously dispersed, smaller size, and spherical-shaped Ag NPs are more effective in biological applications, compared to other morphologies of Ag NPs [10].

Therefore, considering their vast biological applications, economical accessibility, and biocompatibility of Ag NPs is utmost important [11]. However, majority of the physical and/or chemical methods which are commonly applied for the preparation of silver NPs either involve costly apparatus or hazardous chemicals and harsh conditions [12]. Therefore, alternative green methods involving biocompatible materials under facile conditions are more suitable for the synthesis of $\mathrm{Ag}$ NPs targeted for biological applications [13]. In this regards, plant extracts (PE) based synthesis of Ag NPs have gained respectable attention, which contain biologically active phytomolecules that act as both reducing and functionalizing agents [14]. Moreover, PEs are cheaply available, low cost, and are comparatively easy to apply for the eco-friendly preparation of nanomaterials [15].

To date, a variety of PEs have been successfully applied for the preparation of different types of metallic nanomaterials including Ag NPs. For instance, spherical shaped polydispersed Ag NPs of different sizes ranging from 5 to $100 \mathrm{~nm}$, were prepared using aqueous coffee and tea leaf extracts, whereas in other studies fruit extract of Terminalia chebula, and stem bark of Callicarpa main-gayi were applied to obtain biocompatible Ag NPs [16,17]. Similarly, in our previous study, we have successfully used Pulicaria glutinosa, Origanum vulgare, and other PE for the preparation of different sizes and shapes of AgNPs [18,19]. In the present study, we have employed Ziziphus mauritiana leaf extract (ZM-LE), which is commonly referred as Jujube, for the synthesis of silver nanoparticles (ZM-AgNPs). Ziziphus belongs to the family of Rhamnaceae, and has long been used in traditional medicines due to its nutritive and remarkable biological properties [20]. There are more than 40 different species of Ziziphus, which are spread throughout the world and usually require dry conditions to grow [21]. Its plant extract is rich in phytomolecules such as saponins, triterpenes, flavonoids, and alkaloids, along with proteins and a variety of vitamins, due to which it exhibits excellent antioxidant, antimicrobial, antitumor, and anticancer activities $[22,23]$.

Interestingly, Z. mauritiana has been earlier applied for the preparation of other nanomaterials such as zinc oxide and gold NPs [24,25]. Furthermore, very recently ZM-LE has also been successfully used to obtain AgNPs [26]. However, the NPs from this method are prepared applying a photo-reduction method using sun light as reaction medium, which required long reaction time of more than two days. Moreover, the AgNPs obtained from this method are irregularly shaped and large in size. Therefore, herein, we have applied ZM-LE for the aqueous synthesis AgNPs via solution reduction of Ag ion in a short time period (cf. Figure 1). Detail investigation of the effect of time, temperature, and concentration of leaves extract on the properties of resultant NPs is performed. The NPs were identified using different microscopic and spectroscopic techniques. Furthermore, the antibacterial activity of phytomolecules functionalized ZM-AgNPs were tested against various bacterial strains.

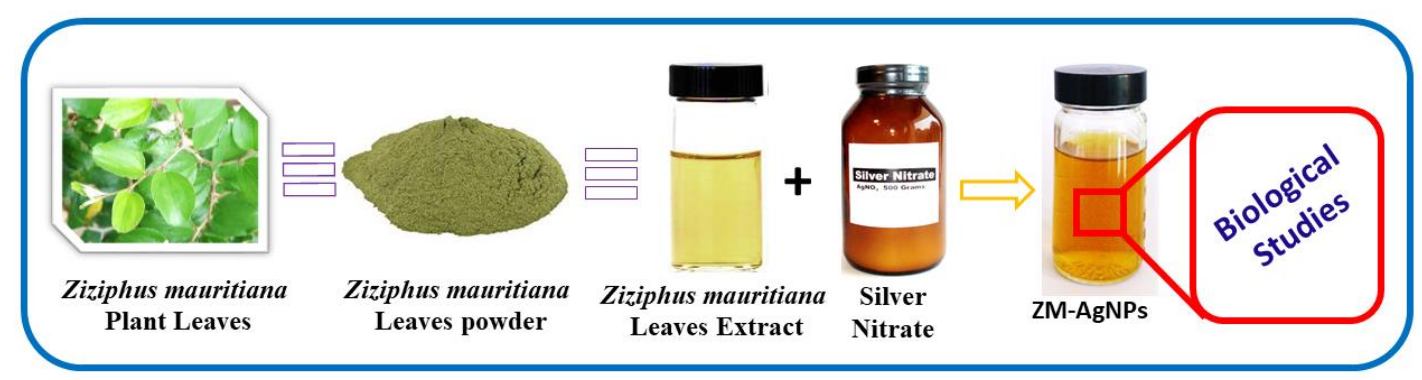

Figure 1. Graphical representation of green synthesized silver nanoparticles (ZM-AgNPs) using Z. mauritiana leaves extract (ZM-LE). 


\section{Experimental}

\subsection{Materials}

Silver nitrate $\left(\mathrm{AgNO}_{3}\right)$ and all the reagents used for phytochemical screening tests were obtained from Sigma Aldrich. Mueller-Hinton agar (MHA) was purchased from Hi-Media Laboratories, Mumbai, India. Plastic wares were obtained from Tarsons Products Pvt. Ltd., India. All solutions were prepared in sterile Milli-Q water. Bacterial strains E. coli (MTCC, No. 1722), S. aureus (MTCC, No. 96), P. aeruginosa (MTCC No. 424), and B. subtilus (MTCC No. 441) were purchased from Microbial Type Culture Collection and Gene Bank (MTCC), Institute of Microbial Technology (IMTECH), Chandigarh, India.

\subsection{Collection and Preparation of Z. mauritiana Leaves Extract}

Fresh leaves of Z. mauritiana (Jujube) are obtained from the JNIAS campus, Hyderabad, Telangana, India. The leaves were washed twice with water and dried for three days before grinding into powder in an electric blender. The aqueous extract of leaves was prepared by mixing $10 \mathrm{~g}$ of leaves powder in $100 \mathrm{~mL}$ of Milli-Q $(100 \mathrm{mg} / \mathrm{mL})$ in a $300 \mathrm{~mL}$ conical flask. The mixture was heated to $\sim 100{ }^{\circ} \mathrm{C}$ for one hour while stirring. Thereafter, the mixture was allowed to cool down to room temperature. The leaves extract is isolated by centrifugation of resultant mixture at $7000 \mathrm{rpm}$ for $20 \mathrm{mins}$. The residual powder was collected by simple decantation and stored in a refrigerator at $4{ }^{\circ} \mathrm{C}$ for further use. Hereafter, the resultant powder is referred to as leaves extract.

\subsection{Leaves Extract Based Synthesis of Silver (Ag) Nanoparticles}

At this stage, $10 \mathrm{~mL}$ of aqueous solution of ZM-LE $(100 \mathrm{mg} / \mathrm{mL})$ was added to $1 \mathrm{mM}$ of $\mathrm{AgNO}_{3}$ solution in $90 \mathrm{~mL}$ of water. The solution was heated to $90{ }^{\circ} \mathrm{C}$ for 30 minutes while stirring. Thereafter, the resulting mixture was incubated for $15 \mathrm{~min}$ at $85^{\circ} \mathrm{C}$. After incubation, the solution was centrifuged at $12000 \mathrm{rpm}$ for 4 minutes, and the obtained precipitate mass i.e., Ag NPs, was washed twice with double distilled water and centrifuged at 12,000 rpm for 3 minutes. The mass was collected and left to dry in a hot air oven at $30-42^{\circ} \mathrm{C}$. After complete drying, the Ag NPs obtained were scraped and stored. In order to optimize the reaction condition for the synthesis of Ag NPs, several reactions were performed by varying different parameters including time, temperature, and concentration of precursors. For example, to optimize the reaction time different reactions were performed using same aforementioned conditions, except that the incubation time was varied between 15 to 120 minutes. Similarly, for the optimization of temperature, the incubation temperature was varied between 25 to $95^{\circ} \mathrm{C}$, while keeping the other parameters constant. Furthermore, to study the effect of the concentration of precursors on the quality of resulting Ag NPs, different reactions were performed by varying the concentrations of $\mathrm{AgNO}_{3}$ and leaves extract. For instance, in these reactions the concentration of $\mathrm{AgNO}_{3}$ was varied between 0.25 and $1.25 \mathrm{mM}$, whereas the leaves extract concentration was varied between 1 and $10 \mathrm{~mL}$.

\subsection{Phytochemical Screening}

Different types of preliminary chemical tests were performed on the Jujube extract to investigate the presences of various secondary metabolites in the Z. mauritiana leaves extract.

\subsubsection{Test for Alkaloids (Mayer's Test)}

At this stage, $1 \mathrm{~mL}(100 \mathrm{mg} / \mathrm{mL})$ of ZM-LE was added into $1 \mathrm{~mL}$ of Mayer's reagent, which led to the formation of white precipitate indicating the presence of alkaloids. Similarly, $1 \mathrm{~mL}$ of Dragendroff reagent was used, which formed brown precipitate in the presence of alkaloids. 


\subsubsection{Test for Flavonoids (Shinoda Test)}

Afterwards, $1 \mathrm{~mL}$ of ZM-LE and few fragments of magnesium metal were added to the test tube followed by dropwise addition of $0.5 \mathrm{~mL}$ of $10 \%$ concentrated $\mathrm{HCl}$. Formation of a reddish color indicates the presence of flavonoids.

\subsubsection{Test for Glycosides (Keller Killani Test)}

A small amount of glacial acetic acid, one drop of $5 \% \mathrm{FeCl}_{3}$ solution and concentrated $\mathrm{H}_{2} \mathrm{SO}_{4}$ was added into $2 \mathrm{~mL}$ of ZM-LE. Reddish brown color appears at the junction of the two liquid layers and the upper layer of bluish green indicates the presence of glycosides.

\subsubsection{Test for Phenols}

Afterwards, $2 \mathrm{~mL}$ of $\mathrm{ZM}$-LE was added to $1 \mathrm{~mL}$ of $\mathrm{H}_{2} \mathrm{SO}_{4}$ and a pinch of $\mathrm{Mg}^{+2}$ metal. Formation of orange or pink color indicates the presence of phenols.

\subsubsection{Folin-Ciocalteu Method}

The total phenolic content in ZM-LE was determined by using Folin-Ciocalteu colorimetric method based on oxidation-reduction reaction. Various concentrations of stock solution (Gallic acid solutions in methanol) $25,50,75,100$, and $200 \mu \mathrm{g} / \mathrm{mL}$ were prepared. In each of the test tube, gallic acid of different concentrations was added and to that $5 \mathrm{~mL}$ of Folin-Ciocalteu reagent and $4 \mathrm{~mL}$ of $7 \% \mathrm{Na}_{2} \mathrm{CO}_{3}$ were added to get a total volume of $10 \mathrm{~mL}$ by using distilled water. The blue colored mixture was shaken well and incubated for 30 minutes at $40{ }^{\circ} \mathrm{C}$ in a water bath. Then the absorbance was measured at $765 \mathrm{~nm}$ against blank. The blank used was distilled water along with FCR and $\mathrm{Na}_{2} \mathrm{CO}_{3}$ and did contain the stock solution. The average absorbance values obtained at different concentrations of gallic acid were used to plot the calibration curve.

\subsubsection{Test for Saponins (Foam Test)}

The $1 \mathrm{~mL}$ of ZM-LE was diluted with $2 \mathrm{~mL}$ of distilled water and was shaken vigorously in a measuring cylinder for 15 minutes. A $1 \mathrm{~cm}$ layer of foam indicates the presence of saponins.

\subsubsection{Test for Sterols (Liebermann-Burchard Test)}

When $1 \mathrm{~mL}$ of $\mathrm{ZM}$-LE was mixed with $1 \mathrm{~mL}$ of acetic acid and $2 \mathrm{~mL}$ of $\mathrm{H}_{2} \mathrm{SO}_{4}$ reddish violet color was obtained, which indicated the presence of sterols.

\subsubsection{Test for Tannins}

Upon addition of 3-4 drops of $10 \% \mathrm{FeCl}_{3}$ to $1 \mathrm{~mL}$ of $\mathrm{ZM}$-LE, greenish or bluish color formed, which indicated the presence of tannins.

\subsection{Characterization}

The as-prepared ZM-AgNPs were identified by using UV-visible spectroscopy, Fourier transform infrared (FTIR), X-ray diffraction analysis (XRD), and scanning electron microscopy (SEM). The bioreduction of $\mathrm{Ag}+$ ions in solutions and the formation of ZM-AgNPs was monitored via UV-Vis spectrophotometer (LIUV-310, Lambda Scientific, Australia). The association of biomolecules with synthesized AgNPs was examined by using a FTIR spectroscope, the Spectrum One (Perkin Elmer, USA) with $\mathrm{KBr}$ pellets. The FTIR spectrum of washed and purified ZM-AgNPs was recorded over the range of $400-4000 \mathrm{~cm}^{-1}$ and the resolution was kept as $4 \mathrm{~cm}^{-1}$. The crystalline nature of synthesized ZM-AgNPs was analyzed on a XRD-6000 X-ray diffractometer model (Shimadzu, Japan) with $40 \mathrm{kV}$, $30 \mathrm{~mA}$ with $\mathrm{Cu}$ ka radiation at $2 \theta$ angle. The morphology of the synthesized ZM-AgNPs was examined by SEM using a SU1510 electron microscope (Hitachi, Japan). TEM images and EDX spectrum were recorded on a JEM 1101 transmission electron microscope (JEOL, Tokyo, Japan). 


\subsection{Antibacterial Properties}

\subsubsection{Inoculums of Microorganism}

Fresh overnight bacterial cultures of four bacterial strains E. coli, S. aureus, P. aeruginosa, and B. subtilis were prepared in a sterile broth at a concentration of $0.5 \mathrm{McF}$ arland $\left(1.5 \times 10^{8} \mathrm{CFU} / \mathrm{mL}\right)$ of UV-Vis spectrophotometer of $600 \mathrm{~nm}$ (LIUV-310, Lambda Scientific, Australia). This suspension was used at different dilutions in the design's proposed evaluation.

\subsubsection{Disc Diffusion Assay}

To analyze the bactericidal activity of ZM-AgNPs, a disc diffusion method was used in line with the previously reported method using various bacterial strains E. coli, S. aureus, P. aeruginosa and B. subtilis [27]. Approximately 15-20 mL of Mulller Hilton Agar (MHR) was transferred into sterilized petri-dishes and the discs (Whatman No-1 filter paper) were utilized to impregnate the ZM-AgNPs solution of various dilutions $(7,14$, and $28 \mu \mathrm{L})$ of $(100 \mu \mathrm{g} / \mathrm{mL})$. Negative control consisted of the $\mathrm{AgNO}_{3}$ solution and Streptomycin $(30 \mu \mathrm{g} / \mathrm{mL})$ as standard. The plates were incubated at $37^{\circ} \mathrm{C}$ for 24 hours and examined for the presence of zones of inhibition. The diameter of such zones of inhibition was measured and expressed in millimeter units.

\subsubsection{Determination of Minimum Inhibitory Concentration (MIC)}

Determination of minimum inhibitory concentration (MIC) assay of different concentration of biosynthesized ZM-AgNPs was analyzed using the method described by reference [28]. The MIC assay was defined as the minimum concentration of a particular antimicrobial agent that can prevent the growth of bacteria. Afterwards, $100 \mu \mathrm{L}$ of E. coli and S. aureus bacterial concentration was inoculated into plates containing Muller Hilton Agar and different concentrations of biosynthesized AgNPs i.e., ZM-AgNPs ( $0,2.5 \mathrm{mg} / \mathrm{mL}, 5 \mathrm{mg} / \mathrm{mL}, 10 \mathrm{mg} / \mathrm{mL}$, and control) suspension was added on plates. The agar plates were incubated at $37^{\circ} \mathrm{C}$ for overnight in an incubator (Thermo Fisher Scientific Co., USA).

\section{Results and Discussion}

\subsection{UV-Vis Analysis}

Z. mauritiana leaves extract (ZM-LE) was applied to prepare biologically active AgNPs under mild conditions. After adding $\mathrm{LE}$ to the aqueous $\mathrm{AgNO}_{3}$ solution and $15 \mathrm{~min}$ incubation, the color of the solution turned to light brown, indicating the successful preparation of ZM-AgNPs (Figure 2). Contrarily, in the absence of $\mathrm{LE}$, no such color change of $\mathrm{AgNO}_{3}$ solution was observed even after incubating the solution for several hours ( $24 \mathrm{hrs}$.). Typically, metal NPs including silver exhibit strong absorption in the visible range due to the surface Plasmon Resonance (SPR) phenomenon [29]. Due to this, the reduction of $\mathrm{Ag}^{+}$ions can be monitored by UV analysis. In the case of the reduction of Ag ions using ZM-LE, the UV spectrum has exhibited a strong absorption peak at $\sim 413 \mathrm{~nm}$, which ultimately confirmed the formation of ZM-AgNPs. Furthermore, the absorption peak at relatively lower wavelength $(413 \mathrm{~nm})$ also points towards the formation of smaller size nanoparticles, as a broader peak higher wavelength typically indicates an enhancement of particle size. For instance, in an earlier study of the photo-reduction of Ag ions using ZM-LE, the UV absorption peak appeared at $\sim 445 \mathrm{~nm}$, which reported the formation of large size $(\sim 85 \mathrm{~nm})$ ZM-AgNPs [26]. 


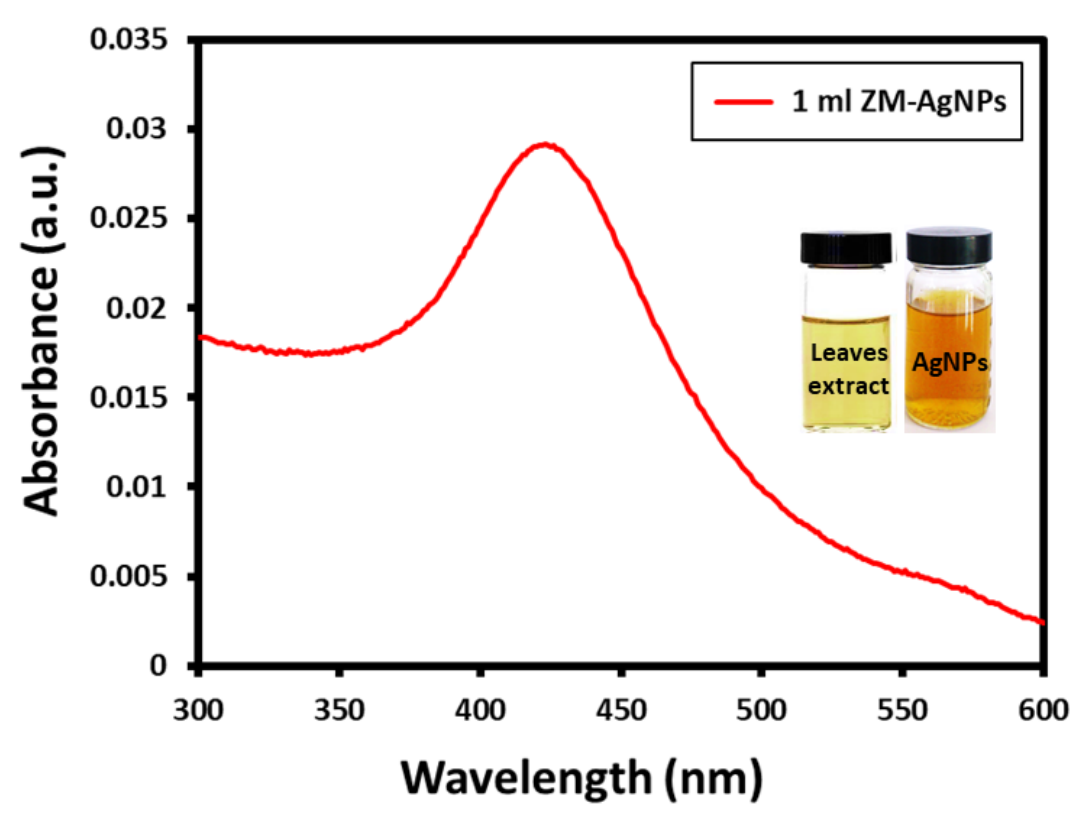

Figure 2. UV-Vis analysis of as-synthesized silver nanoparticles (1 mL ZM-AgNPs) using ZM-LE.

The amount of reducing agent (ZM-LE) was optimized via preparation of AgNPs using different concentrations of ZM-LE, such as $1 \mathrm{~mL}, 2.5 \mathrm{~mL}, 5 \mathrm{~mL}, 7.5 \mathrm{~mL}$, and $10 \mathrm{~mL}$. The results were monitored using UV (cf. Figure 3), upon increasing the concentration of ZM-LE, the absorption bands broadened and shifts towards the higher wavelength which was indicative of the deterioration of the quality of NPs [30]. Indeed, at higher concentrations of ZM-LE above $5 \mathrm{~mL}$, the reaction ceased to occur due to the presence of excess amount of bio-reductant. Therefore, low concentration of ZM-LE, i.e., below $5 \mathrm{~mL}$, was sufficient to obtain high quality of NPs. Besides this, a comparative investigation was also performed to study the influence of the concentration of silver precursor $\left(\mathrm{AgNO}_{3}\right)$, for which various experiments were performed using different concentrations of $\mathrm{AgNO}_{3}(0.25 \mathrm{mM}, 0.5 \mathrm{mM}$, $0.75 \mathrm{mM}, 1.0 \mathrm{mM}$, and $1.25 \mathrm{mM}$ ), while keeping the amount of ZM-LE constant at $1 \mathrm{~mL}$. AgNPs were not formed at the lowest concentration of $\mathrm{AgNO}_{3}(0.25 \mathrm{mM})$, as substantiated by the UV spectrum. Whereas upon increasing the concentration of $\mathrm{AgNO}_{3}$, a shift in the SPR band was observed, initially it was obtained at $406 \mathrm{~nm}(0.5 \mathrm{mM})$ and shifted to $413 \mathrm{~nm}(1.25 \mathrm{mM})$, indicating a slight increase in particle size with an increase in the concentration of precursor. In addition, the effect of time and temperature on the synthesis of AgNPs using ZM-LE is also investigated using UV analysis and the data is provided in the supporting information. It was revealed that temperatures above $65{ }^{\circ} \mathrm{C}$ (best results at $95^{\circ} \mathrm{C}$ ) and a time of 15 minutes are optimum to prepare a good quality of AgNPs (data not shown). 

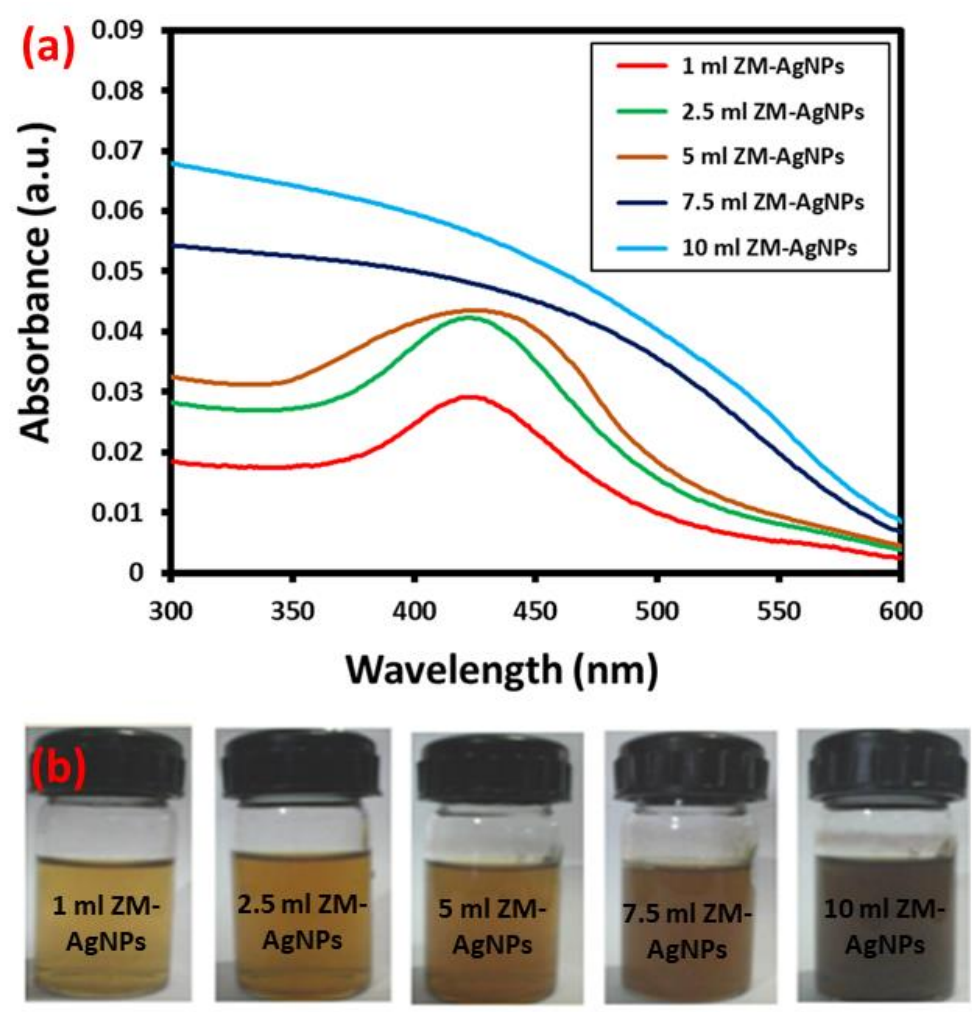

Figure 3. (a) UV-Vis analysis of as-synthesized silver nanoparticles (ZM-AgNPs) using various concentrations of ZM-LE (1, 2.5, 5, 7.5, and $10 \mathrm{~mL})$ and $(\mathbf{b})$ dispersion images of as-synthesized silver nanoparticles using various concentrations of ZM-LE $(1,2.5,5,7.5$, and $10 \mathrm{~mL})$.

\subsection{XRD Analysis}

The crystallinity of Ag NPs obtained via ZM-LE was confirmed using XRD as shown in Figure 4. The as-obtained ZM-AgNPs exhibited cubic structure, clearly reflected by the presence of five characteristic peaks in the XRD pattern such as, $37.50^{\circ}(111), 44.13^{\circ}(200), 63.91^{\circ}(220), 76.89^{\circ}(311)$, and $81.13^{\circ}$ (222). Apart from the distinct peaks of ZM-AgNPs, the absence of any other additional peaks clearly indicated that the lattice of as-obtained ZM-AgNPs was unaffected by other molecules in the leaves extract. Furthermore, the average crystallite size was calculated using the Debye-Scherrer formula, $D=k \lambda / \beta \cos \theta$, where $D$ is the diameter of the particle, $k$ is constant (1), $\lambda=0.1541 \mathrm{~nm}(\mathrm{Cu} \mathrm{Ka})$, $\beta$ is FWHM, and ' $\theta$ ' is the diffraction angle corresponding to the lattice plane (1 111 ). The average size is found to be $61 \mathrm{~nm}$, which is slightly higher when compares to the size of the particles obtained by TEM. This could be due the slight deviation from the ideal shape (spherical) of the particles considered in the Debye-Scherrer formula.

The morphology of the as-prepared ZM-AgNPs observed under TEM and the corresponding particle size distribution are shown in Figure 5. The TEM results clearly indicated that the particles are of spherical shape with small size ranging from 3-20 nm, retaining a narrow size distribution (Figure 5). Moreover, the nanoparticles are largely well separated and only a few of them were agglomerated. The surface morphology of the as-synthesized ZM-AgNPs was also monitored using scanning electron microscopy (SEM), as shown in Figure 6. The image obtained clearly demonstrated the spherical shape of the nanoparticles. Additionally, the elemental composition determined by using EDX also indicated the presence of Ag as major element in the sample (cf. Figure 6). Apart from Ag, the EDX spectrum also pointed towards the presence of carbon and oxygen in the sample; this outcome could be attributed to the existence of residual phytomolecules on the surface of resulting ZM-AgNPs as stabilizing ligands. 


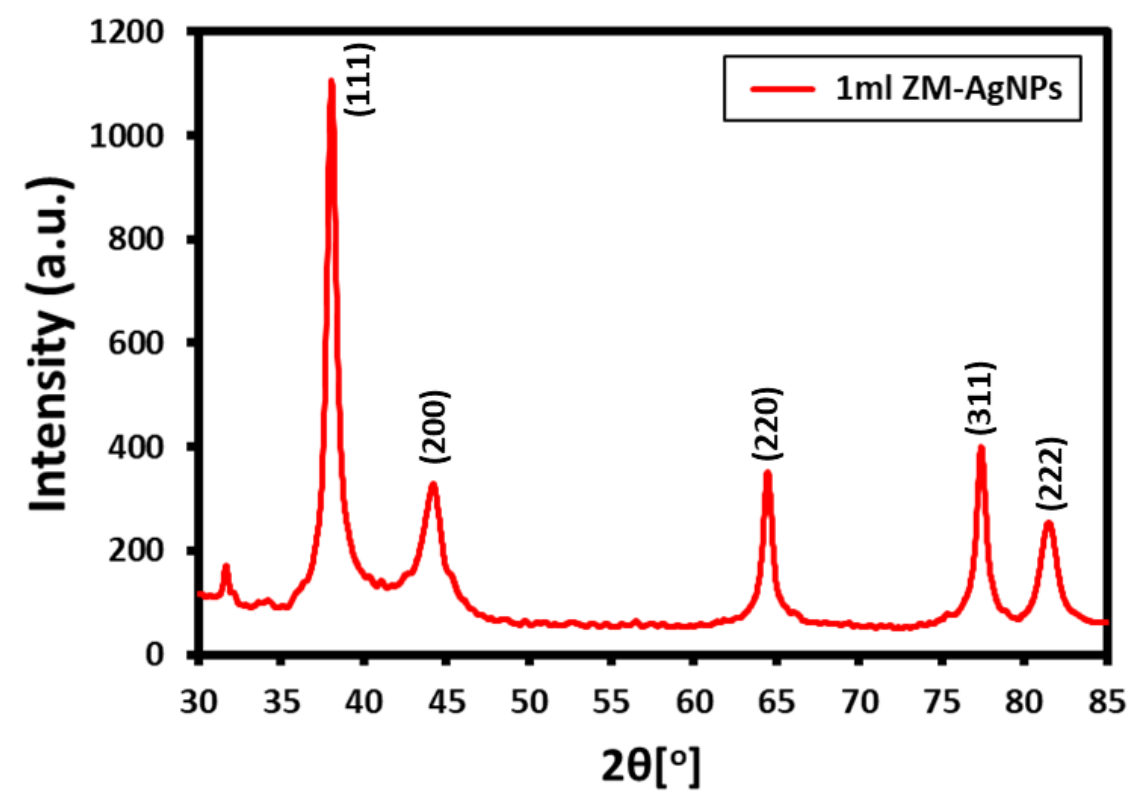

Figure 4. XRD analysis of as-synthesized silver nanoparticles (1 mL ZM-AgNPs) using $1 \mathrm{~mL}$ ZM-LE.
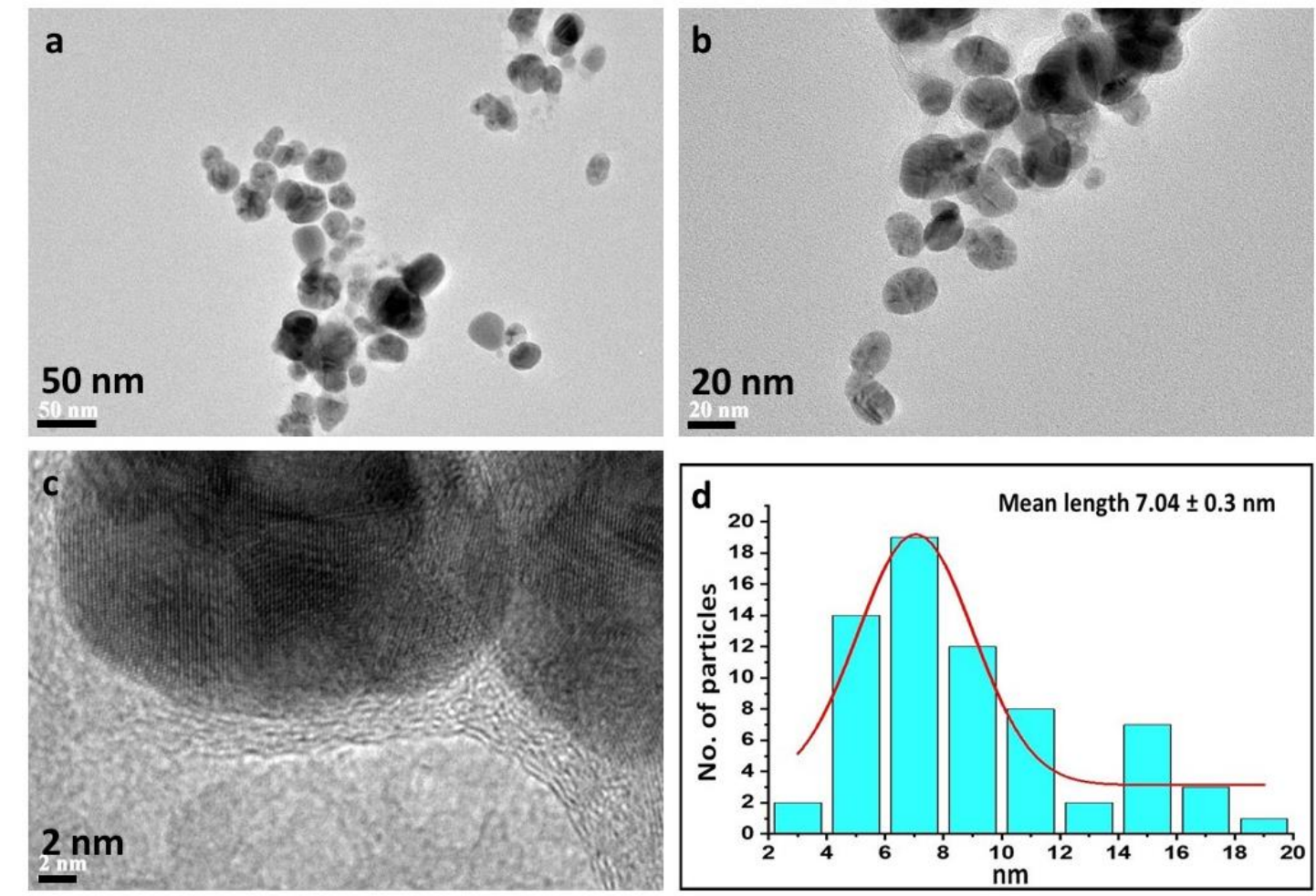

Figure 5. TEM images of as-synthesized silver nanoparticles using $1 \mathrm{~mL} Z \mathrm{ZM}-\mathrm{AgNPs}(\mathbf{a}, \mathbf{b})$ overview, (c) magnified TEM image, and (d) particle size distribution graph. 

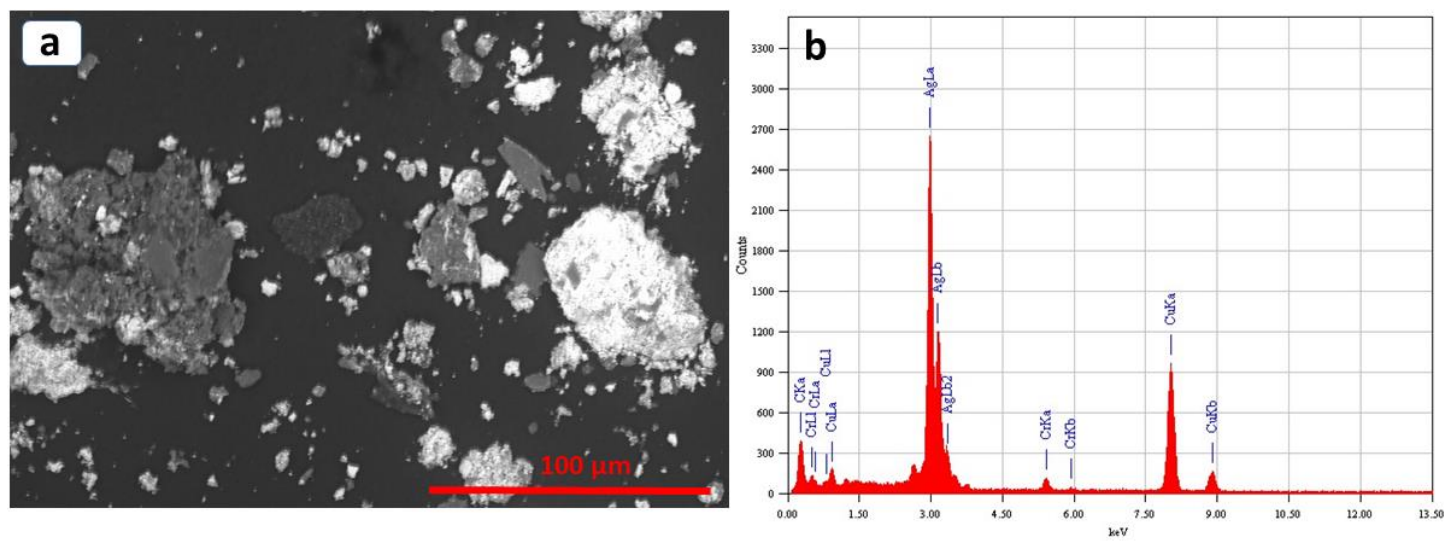

Figure 6. (a) SEM images of as-synthesized silver nanoparticles using $1 \mathrm{~mL}$ ZM-AgNPs and (b) EDX analysis of $1 \mathrm{~mL}$ ZM-AgNPs.

\subsection{Preliminary Identification of Phytomolecules on the Surface of ZM-AgNPs}

In order to determine the active phytomolecules responsible for the reduction of silver ions, a preliminary qualitative analysis of ZM-LE was performed which helped to detect the secondary metabolites present in Ziziphus mauritiana extract. For this purpose, various tests were performed, such as the Mayer's test, Shinoda test, Keller Killani test, Foam test, Liebermann-Burchard Test, etc., which pointed towards the presence of various secondary metabolites including alkaloids, phenols, tannins, saponins and glycosides in the ZM-LE. All these tests were successful in ascertaining the presence of these secondary metabolites in the ZM-LE.

Additionally, the determination of total polyphenol's contents in extracts was made according to the Folin-Ciocalteu method by measuring the absorbance at $765 \mathrm{~nm}$ against a control without extract [31]. This technique has been reportedly used in several studies to determine the total phenolic contents of the plant extracts. For example, Kumar et al., have reported the total phenolic contents of 23 and 40 mg per gram in the leaves and stem extracts of Syzygium cumini plant, which were employed for the synthesis of Ag NPs. During this study, they suggested a direct correlation between the total phenolic contents and the size of resulting NPs, which increases with the increase of phenolic contents [32]. In another study, Folin-Ciocalteu method was used to determine the presence of phenolic contents on the surface of resulting silver NPs. Approximately $7.7 \mathrm{mg}$ of phenolic contents were found as stabilizing ligands on the surface of Ag NPs prepared from the Potentilla fulgens wall plant extract [33]. In this study, the total polyphenol's content in the ZM-LE (at final concentration $100 \mathrm{mg} / \mathrm{mL}$ ) was calculated from a linear calibration curve $(y=m x+c)$, established with gallic acid $(0-100 \mu \mathrm{g} / \mathrm{mL})$ as a standard reference in the same conditions as the sample [34]. Meanwhile, the $\mathrm{AlCl}_{3}$ method was used to determine the total flavonoids contents in the ZM-LE [35]. The results have revealed a total phenolic contents quantity of $32.1 \mathrm{mg} / \mathrm{g}$ of ZM-LE, as well as $533.5 \mathrm{mg} / \mathrm{g}$ of flavonoid contents. Indeed, various phytomolecules belonging to polyphenols and flavonoids were also found to be present on the surface of resultant ZM-AgNPs which were prepared by using ZM-LE extract.

This was further confirmed by FT-IR analysis, which was used to identify the presence of residual biomolecules of ZM-LE on the surface of ZM-AgNPs as stabilizing agents. In order to remove the unbound phytomolecules, the sample was washed repeatedly before FT-IR measurement. For instance, freshly obtained ZM-AgNPs were redispersed in DI water through sonication (30 min), and centrifuged at $9000 \mathrm{rpm}$ (30 $\mathrm{min})$, and this procedure was performed twice to obtain pure ZM-AgNPs for IR measurement. Figure 7 exhibits the IR spectra of purified NPs. The FT-IR spectrum ZM-AgNPs exhibited several peaks, which indicates the presence of several important functional groups. Some of the prominent peaks include the peaks at 3747, 3441,1761,1629,1407, 1255, 1070, and $512 \mathrm{~cm}^{-1}$ which can be attributed to the hydrogen bonded $\mathrm{O}-\mathrm{H}$ group, $\mathrm{C}-\mathrm{H}, \mathrm{C}-\mathrm{C}$, and $\mathrm{C}-\mathrm{O}$ stretching of aromatics, $\mathrm{C}-\mathrm{O}$ stretching of alcohols, carboxylic acids, and ester groups, etc. [36]. In addition, these peaks 
revealed the presence of different compounds containing carbon and oxygen, thereby suggesting that silver nanoparticles might be capped by organic components of ZM-LE, which not only help to stabilize the surface of NPs, but also enhance the biological properties of these materials.

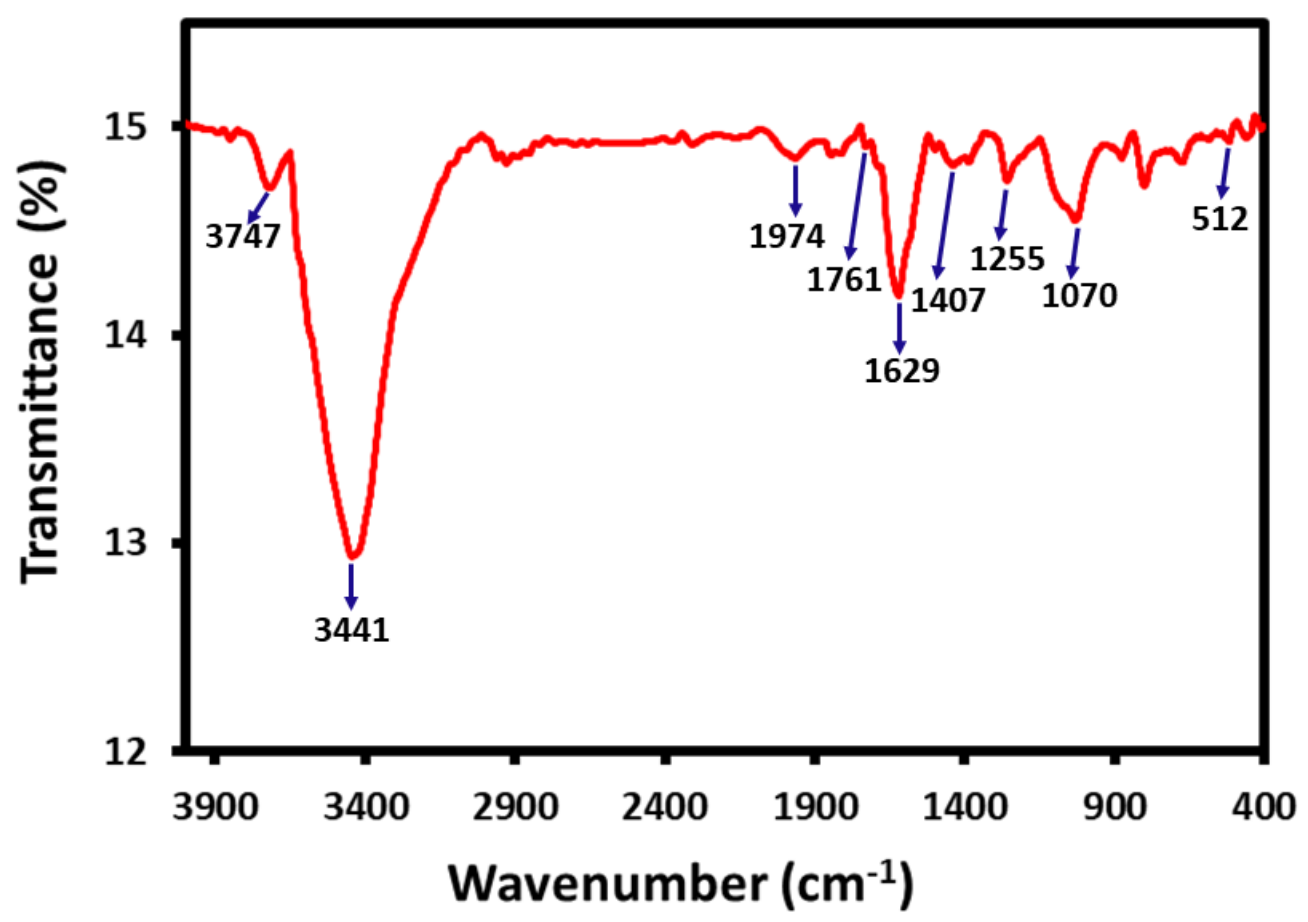

Figure 7. FT-IR spectra of as-synthesized silver nanoparticles $1 \mathrm{~mL}$ ZM-AgNPs.

\subsection{Antimicrobial Properties}

The antibacterial assay of ZM-AgNPs was performed against antibiotic resistant gram positive bacterial strains such as $S$. aureus, B. subtilus, and gram negative bacterial strains such as $P$. aeruginosa and E. coli, using the disc diffusion method. Streptomycin was employed as a control and the zone of inhibition value was calculated for different concentrations of ZM-AgNPs i.e., $7 \mu \mathrm{L}, 14 \mu \mathrm{L}$, and $28 \mu \mathrm{L}$ from $(100 \mu \mathrm{g} / \mathrm{mL})$. The different zones of inhibition obtained are given in Figure 8.

From the results obtained, it can be understood that the highest zone of inhibition of about $28 \mathrm{~mm}$ was recorded in the case of biosynthesized AgNPs at the dilution of $28 \mu \mathrm{g} / \mathrm{mL}$ against S. aureus, a gram positive bacterial strain, which is much higher than the zone of inhibition obtained using the control i.e., Streptomycin. Moreover, upon a decrease in the concentration of ZM-AgNPs, the zone of inhibition also decreased. The values obtained as a result are given in Table 1 and can be seen in Figure $8 \mathrm{~A}$. Furthermore, in case of activity against B. subtilis, a gram positive bacterial strain, the zone of inhibition obtained was found to be comparable to the one obtained using the control (Figure 8B). When the study was extended to gram negative bacterial strains such as P. aeruginosa and E. coli, the zone of inhibition obtained was found to be $21 \mathrm{~mm}$ and $22 \mathrm{~mm}$, respectively, which is much smaller than that obtained using the control i.e., $26 \mathrm{~mm}$ and $28 \mathrm{~mm}$ (Figure $8 \mathrm{C}$ and D). From the above results, it can be concluded that the ZM-AgNPs display selective activity against $S$. aureus. 


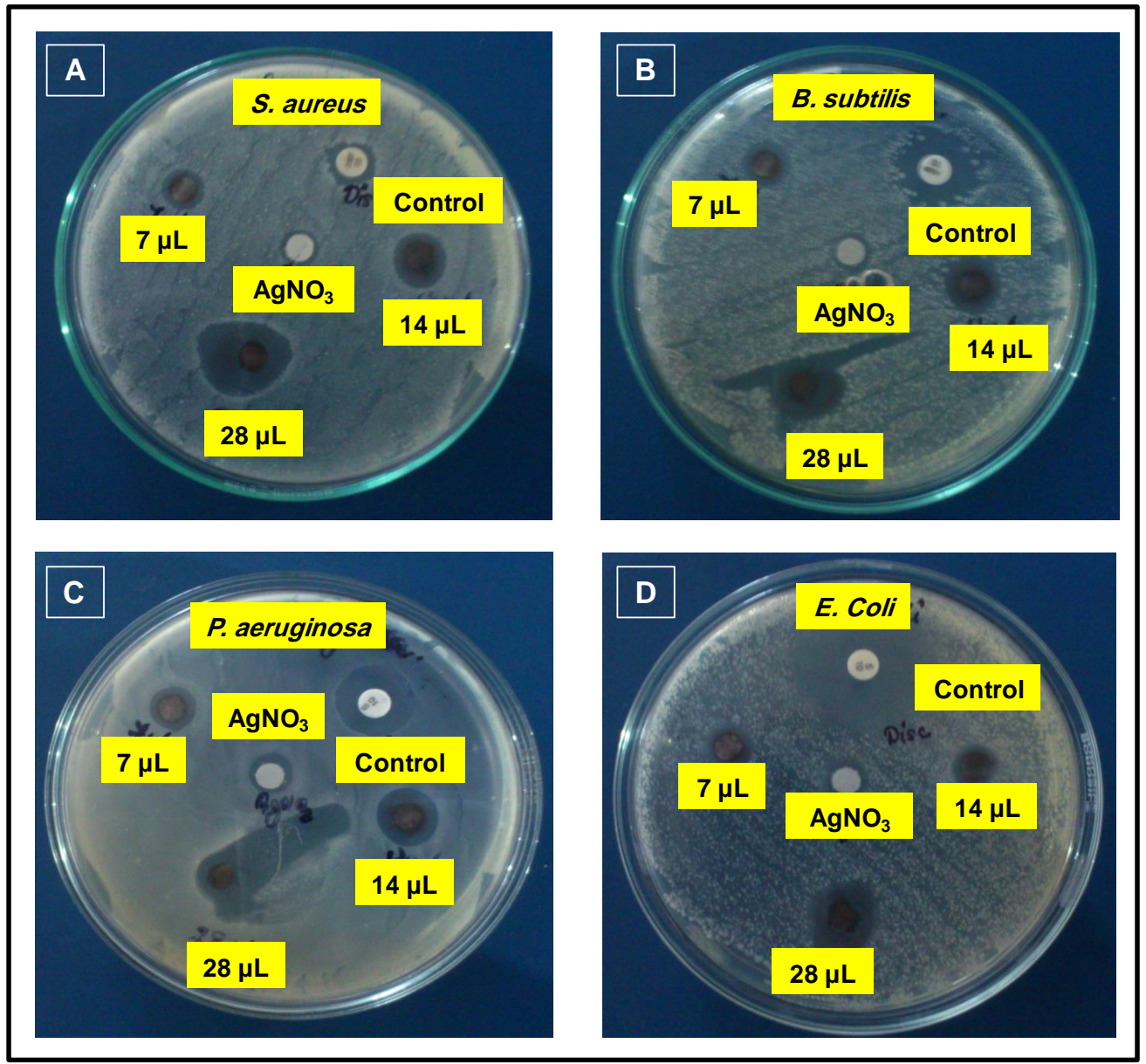

Figure 8. Images of zone of inhibition obtained when the disc diffusion method is employed for the antibacterial study of biosynthesized ZM-AgNPs against gram-positive bacterial strains: (A) S. aureus; (B) B. subtilis and gram-negative bacterial strains; (C) P. aeruginosa; (D) E. coli.

Table 1. Effect of varying concentrations of biosynthesized ZM-AgNPs as antimicrobial agents against S. aureus, B. subtilus, P. aeruginosa, and E. coli bacterial strains.

\begin{tabular}{|c|c|c|c|c|c|c|}
\hline \multicolumn{7}{|c|}{ Zone of Inhibition (mm) } \\
\hline & \multirow{2}{*}{ Bacterial Strains } & \multirow{2}{*}{ Control } & \multirow{2}{*}{$\begin{array}{c}\mathrm{AgNO}_{3} \\
\text { Solution }\end{array}$} & \multicolumn{3}{|c|}{ ZM-AgNPs } \\
\hline & & & & $7 \mu \mathrm{L}$ & $14 \mu \mathrm{L}$ & $28 \mu \mathrm{L}$ \\
\hline \multirow{2}{*}{$\begin{array}{l}\text { Gram } \\
+v e\end{array}$} & S. aureus (MTCC No. 96) & 8 & 3 & 8 & 16 & 28 \\
\hline & B. subtilus (MTCC No. 441) & 26 & 4 & 10 & 18 & 26 \\
\hline Gram & P. aeruginosa (MTCC No. 424) & 26 & 4 & 9 & 19 & 21 \\
\hline$-v e$ & E. coli (MTCC No. 1722) & 28 & 4 & 8 & 12 & 22 \\
\hline
\end{tabular}

The high activity of ZM-AgNPs in case of $S$. aureus bacterial strain can be attributed to their excellent tendency of adsorbing on the bacterial cell wall and undergo dehydrogenation due to the respiration process which occurs at the cell membrane of bacteria. Due to the interaction with nanoparticles, the enzymes in the bacteria are deactivated, generating a hydrogen peroxide that eventually leads to microbial cell death [37]. However, similar nanoparticles were prepared with dragon fruit peel extract and were tested for microcidal activity against the same bacterial strains as the ones we obtained; however, it was found that Ag NPs prepared by the dragon fruit peel extract yielded a zone of inhibition of $9 \mathrm{~mm}$, while the Ag NPs reported in this study yielded a significantly higher zone of inhibition i.e., $22 \mathrm{~nm}$ [38]. 
Furthermore, the minimum inhibitory concentration (MIC) value of biosynthesized ZM-AgNPs was calculated and the bacterial strains $S$. aureus and E. coli were selected for this study. In this study the bacterial strains, the E. coli and $S$. aureus were subjected to different concentrations of ZM-AgNPs $(0,2.5 \mu \mathrm{g} / \mathrm{ml}, 5 \mu \mathrm{g} / \mathrm{ml}, 10 \mu \mathrm{g} / \mathrm{ml})$ and were also taken as controls without ZM-AgNPs. The ZM-AgNPs showed the highest level of activity against E. coli with the MIC value of $5 \mu \mathrm{g} / \mathrm{mL}$, while for $S$. aureus, the MIC value was found to be $10 \mu \mathrm{g} / \mathrm{mL}$, as shown in Figure 9.

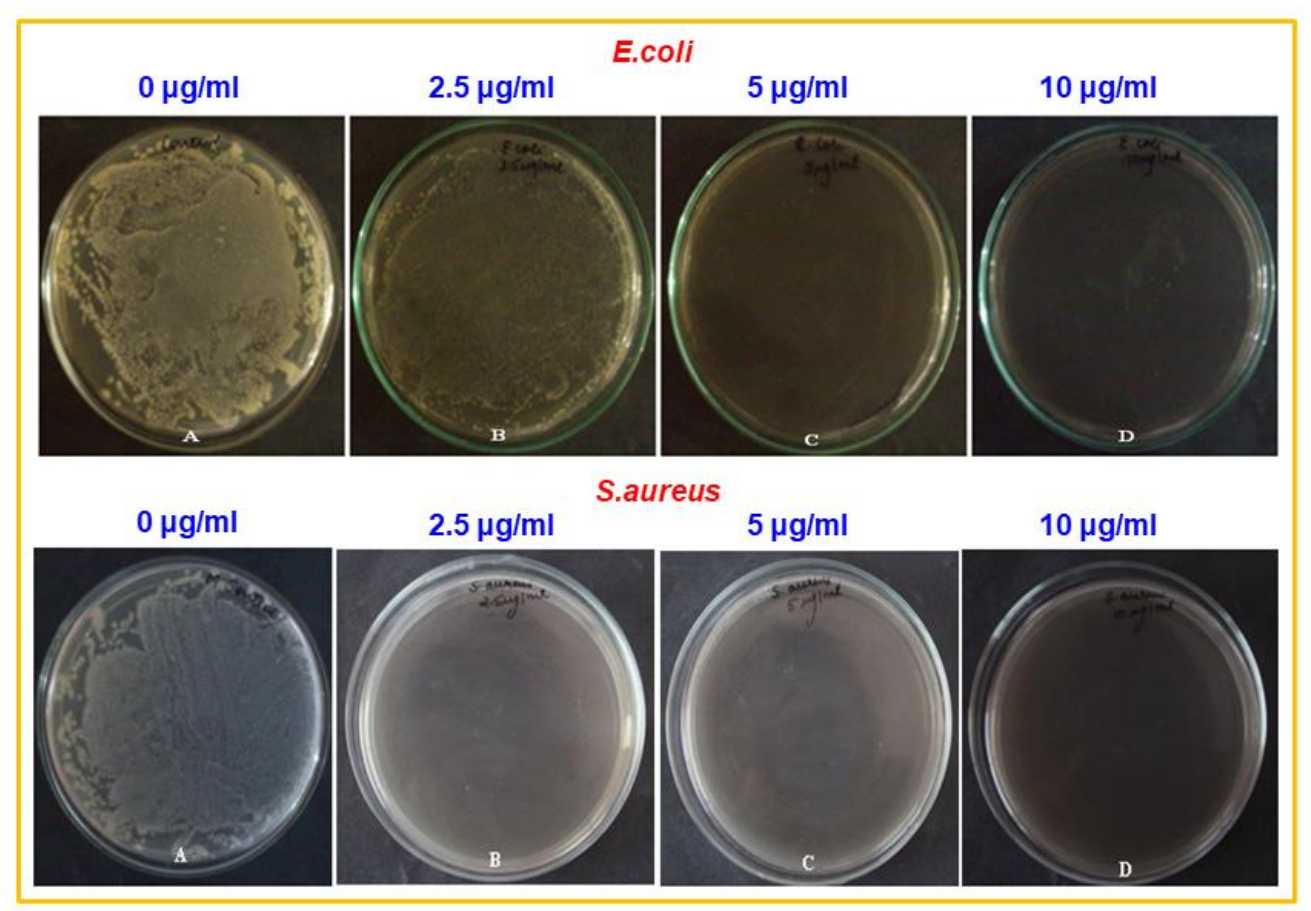

Figure 9. Effect of varying concentrations $(2.5 \mu \mathrm{g} / \mathrm{mL}, 5 \mu \mathrm{g} / \mathrm{mL}$, and $10 \mu \mathrm{g} / \mathrm{mL})$ of biosynthesized ZM-AgNPs against bacterial strains E. coli and S. aureus.

\section{Conclusions}

In brief, we have succeeded in achieving the green reduction of silver ions by Z. mauritiana leaves extract under ambient conditions in a short period of time. The characterization of green synthesized ZM-AgNPs was performed by UV-Vis spectroscopy, FT-IR, XRD, SEM, and TEM analysis. The results have revealed the formation of spherical shape Ag NPs with an average size of $12.5 \mathrm{~nm}$. Moreover, the presence of phenolic compounds and the flavonoid contents in the ZM-LE extract were confirmed by Folin-Ciocalteu and $\mathrm{AlCl}_{3}$ methods, which were believed to be responsible for the reduction of silver ions. In this method, we have successfully reduced the preparation time from a couple of days using the photo-reduction method to $15 \mathrm{~min}$ by using ZM-LE. Additionally, the antibacterial properties, the zone of inhibition, and the minimum inhibitory concentration of biosynthesized ZM-AgNPs showed the inhibitory effect against all tested bacteria in a short time; however, the ZM-AgNPs were found to be selective against $S$. aureus, a gram positive bacterial strain.

Author Contributions: M.A., K.J. and M.K. contributed towards the designing of the project. M.A., M.R.S., N.F., M.S.A. and S.F.A. contributed towards the experimental and characterization. M.K., M.R.S. and S.F.A. contributed towards the drafting of the manuscript. K.J., M.K. and M.R.H.S. provided scientific guidance for successful completion of the project and also helped to draft the manuscript. All authors read and approved the final manuscript.

Funding: Researchers Supporting Project Number (RSP-2019/60), King Saud University, Riyadh, Saudi Arabia.

Acknowledgments: The authors would like to extend their sincere appreciation to the Researchers Supporting Project Number (RSP-2019/60), King Saud University, Riyadh, Saudi Arabia.

Conflicts of Interest: The authors declare no conflict of interest. 


\section{References}

1. Gao, J.; Gu, H.; Xu, B. Multifunctional Magnetic Nanoparticles: Design, Synthesis, and Biomedical Applications. Acc. Chem. Res. 2009, 42, 1097-1107. [CrossRef] [PubMed]

2. Vinci, G.; Rapa, M. Noble Metal Nanoparticles Applications: Recent Trends in Food Control. Bioengineering 2019, 6, 10. [CrossRef] [PubMed]

3. Ocsoy, I.; Tasdemir, D.; Mazicioglu, S.; Celik, C.; Katı, A.; Ulgen, F. Biomolecules incorporated metallic nanoparticles synthesis and their biomedical applications. Mater. Lett. 2018, 212, 45-50. [CrossRef]

4. Khan, M.; Al-Marri, A.H.; Khan, M.; Mohri, N.; Adil, S.F.; Al-Warthan, A.; Siddiqui, M.R.H.; Alkhathlan, H.Z.; Berger, R.; Tremel, W.; et al. Pulicaria glutinosa plant extract: A green and eco-friendly reducing agent for the preparation of highly reduced graphene oxide. RSC Adv. 2014, 4, 24119-24125. [CrossRef]

5. Chernousova, S.; Epple, M. ChemInform Abstract: Silver as Antibacterial Agent: Ion, Nanoparticle, and Metal. Angew. Chem. Int. Ed. 2013, 44, 1636-1653. [CrossRef]

6. Franci, G.; Falanga, A.; Galdiero, S.; Palomba, L.; Rai, M.; Morelli, G.; Galdiero, S. Silver Nanoparticles as Potential Antibacterial Agents. Molecules 2015, 20, 8856-8874. [CrossRef]

7. Rigo, C.; Ferroni, L.; Tocco, I.; Roman, M.; Munivrana, I.; Gardin, C.; Cairns, W.R.L.; Vindigni, V.; Azzena, B.; Barbante, C.; et al. Active Silver Nanoparticles for Wound Healing. Int. J. Mol. Sci. 2013, 14, 4817-4840. [CrossRef]

8. Ho, C.H.; Odermatt, E.K.; Berndt, I.; Tiller, J.C. Long-term active antimicrobial coatings for surgical sutures based on silver nanoparticles and hyperbranched polylysine. J. Biomater. Sci. Polym. Ed. 2013, 24, 1589-1600. [CrossRef]

9. Zhang, X.-F.; Liu, Z.; Shen, W.; Gurunathan, S. Silver Nanoparticles: Synthesis, Characterization, Properties, Applications, and Therapeutic Approaches. Int. J. Mol. Sci. 2016, 17, 1534. [CrossRef]

10. MubarakAli, D.; Thajuddin, N.; Jeganathan, K.; Gunasekaran, M. Plant extract mediated synthesis of silver and gold nanoparticles and its antibacterial activity against clinically isolated pathogens. Colloids Surf. B Biointerfaces 2011, 85, 360-365. [CrossRef]

11. Vasilev, K.; Cavallaro, A.; Zilm, P. Special Issue: Antibacterial Materials and Coatings. Molecules 2018, 23, 585. [CrossRef]

12. Adil, S.F.; Assal, M.E.; Khan, M.; Al-Warthan, A.; Siddiqui, M.R.H.; Liz-Marzán, L.M. Biogenic synthesis of metallic nanoparticles and prospects toward green chemistry. Dalton Trans. 2015, 44, 9709-9717. [CrossRef]

13. Shah, M.; Fawcett, D.; Sharma, S.; Tripathy, S.K.; Poinern, G. Green Synthesis of Metallic Nanoparticles via Biological Entities. Materials 2015, 8, 7278-7308. [CrossRef]

14. Akhtar, M.S.; Panwar, J.; Yun, Y.-S. Biogenic Synthesis of Metallic Nanoparticles by Plant Extracts. ACS Sustain. Chem. Eng. 2013, 1, 591-602. [CrossRef]

15. Khan, M.; Shaik, M.R.; Adil, S.F.; Khan, S.T.; Al-Warthan, A.A.; Siddiqui, M.R.H.; Tahir, M.N.; Tremel, W.; Siddiqui, R.H. Plant extracts as green reductants for the synthesis of silver nanoparticles: Lessons from chemical synthesis. Dalton Trans. 2018, 47, 11988-12010. [CrossRef]

16. Nadagouda, M.N.; Varma, R.S. Green synthesis of silver and palladium nanoparticles at room temperature using coffee and tea extract. Green Chem. 2008, 10, 859. [CrossRef]

17. Nishibuchi, M.; Chieng, B.W.; Loo, Y.Y.; Radu, S. Synthesis of silver nanoparticles by using tea leaf extract from Camellia Sinensis. Int. J. Nanomed. 2012, 7, 4263-4267. [CrossRef] [PubMed]

18. Siddiqui, M.R.H.; Khan, M.; Khan, M.; Adil, S.F.; Tahir, M.N.; Tremel, W.; Alkhathlan, H.Z.; Al-Warthan, A. Green synthesis of silver nanoparticles mediated by Pulicaria glutinosa extract. Int. J. Nanomed. 2013, 8, 1507-1516. [CrossRef] [PubMed]

19. Shaik, M.R.; Khan, M.; Kuniyil, M.; Kuniyil, M.; Alkhathlan, H.Z.; Siddiqui, M.R.H.; Shaik, J.P.; Ahamed, A.; Mahmood, A.; Khan, M.; et al. Plant-Extract-Assisted Green Synthesis of Silver Nanoparticles Using Origanum vulgare L. Extract and Their Microbicidal Activities. Sustainability 2018, 10, 913. [CrossRef]

20. Parmar, P.; Bhatt, S.; Dhyani, S.; Jain, A. Phytochemical studies of the secondary metabolites of Ziziphus mauritiana Lam. Leaves. Int. J. Curr. Pharm. Res. 2012, 4, 153-155.

21. Mahajan, R.T.; Chopda, M. Phyto-Pharmacology of Ziziphus jujuba Mill-A plant review. Pharmacogn. Rev. 2009, 3, 320. 
22. Choi, S.-H.; Ahn, J.-B.; Kozukue, N.; Levin, C.; Friedman, M. Distribution of Free Amino Acids, Flavonoids, Total Phenolics, and Antioxidative Activities of Jujube (Ziziphus jujuba) Fruits and Seeds Harvested from Plants Grown in Korea. J. Agric. Food Chem. 2011, 59, 6594-6604. [CrossRef]

23. Gao, Q.-H.; Wu, C.-S.; Wang, M. The Jujube (Ziziphus Jujuba Mill.) Fruit: A Review of Current Knowledge of Fruit Composition and Health Benefits. J. Agric. Food Chem. 2013, 61, 3351-3363. [CrossRef] [PubMed]

24. Sadeghi, B. Zizyphus mauritiana extract-mediated green and rapid synthesis of gold nanoparticles and its antibacterial activity. J. Nanostruct. Chem. 2015, 5, 265-273. [CrossRef]

25. Padalia, H.; Chanda, S. Characterization, antifungal and cytotoxic evaluation of green synthesized zinc oxide nanoparticles using Ziziphus nummularia leaf extract. Artif. Cells Nanomed. Biotechnol. 2017, 45, 1751-1761. [CrossRef]

26. Al-Bahrani, R.M.; Majeed, S.M.A.; Owaid, M.; Mohammed, A.B.; Rheem, D.A. Phyto-fabrication, characteristics and anticandidal effects of silver nanoparticles from leaves of Ziziphus mauritiana lam. Acta Pharm. Sci. 2018, 56, 85. [CrossRef]

27. Saifuddin, N.; Wong, C.W.; Yasumira, A.A.N. Rapid Biosynthesis of Silver Nanoparticles Using Culture Supernatant of Bacteria with Microwave Irradiation. E-J. Chem. 2009, 6, 61-70. [CrossRef]

28. Ansari, M.; Khan, H.; Khan, A.; Malik, A.; Sultan, A.; Shahid, M.; Shujatullah, F.; Azam, A. Evaluation of antibacterial activity of silver nanoparticles against MSSA and MSRA on isolates from skin infections. Biol. Med. 2011, 3, 141-146.

29. Sathishkumar, G.; Gobinath, C.; Karpagam, K.; Hemamalini, V.; Kumpati, P.; Sivaramakrishnan, S. Phyto-synthesis of silver nanoscale particles using Morinda citrifolia L. and its inhibitory activity against human pathogens. Colloids Surf. B Biointerfaces 2012, 95, 235-240. [CrossRef]

30. Smitha, S.; Nissamudeen, K.; Philip, D.; Gopchandran, K.; Gopalan, G.K. Studies on surface plasmon resonance and photoluminescence of silver nanoparticles. Spectrochim. Acta Part A Mol. Biomol. Spectrosc. 2008, 71, 186-190. [CrossRef]

31. Singleton, V.L.; Orthofer, R.; Lamuela-Raventós, R.M. [14] Analysis of total phenols and other oxidation substrates and antioxidants by means of folin-ciocalteu reagent. Methods Enzymol. 1999, 299, 152-178.

32. Kumar, V.; Yadav, S.C.; Yadav, S.K. Syzygium cumini leaf and seed extract mediated biosynthesis of silver nanoparticles and their characterization. J. Chem. Technol. Biotechnol. 2010, 85, 1301-1309. [CrossRef]

33. Mittal, A.K.; Tripathy, D.; Choudhary, A.; Aili, P.K.; Chatterjee, A.; Singh, I.P.; Banerjee, U.C. Bio-synthesis of silver nanoparticles using Potentilla fulgens Wall. ex Hook. and its therapeutic evaluation as anticancer and antimicrobial agent. Mater. Sci. Eng. C 2015, 53, 120-127. [CrossRef] [PubMed]

34. Hafsé, M.; Farah, A.; Benbrahim, K.F. Evaluation of the antibacterial activity and determination of polyphenols and flavonoids contents of Moroccan Coriaria myrtifolia extracts. Int. J. Pharm. Pharm. Sci. 2015, 7, 108-111.

35. Warburton, E.; Norris, P.L.; Goenaga-Infante, H. Comparison of the capabilities of accelerated solvent extraction and sonication as extraction techniques for the quantification of kavalactones in Piper methysticum (Kava) roots by high performance liquid chromatography with ultra violet detection. Phytochem. Anal. 2007, 18, 98-102. [CrossRef]

36. Shameli, K.; Bin Ahmad, M.; Zamanian, A.; Sangpour, P.; Shabanzadeh, P.; Abdollahi, Y.; Zargar, M. Green biosynthesis of silver nanoparticles using Curcuma longa tuber powder. Int. J. Nanomed. 2012, 7, 5603-5610. [CrossRef]

37. Li, W.-R.; Xie, X.-B.; Shi, Q.-S.; Zeng, H.-Y.; You-Sheng, O.-Y.; Chen, Y.-B. Antibacterial activity and mechanism of silver nanoparticles on Escherichia coli. Appl. Microbiol. Biotechnol. 2010, 85, 1115-1122. [CrossRef]

38. Phongtongpasuk, S.; Poadang, S.; Yongvanich, N. Environmental-friendly Method for Synthesis of Silver Nanoparticles from Dragon Fruit Peel Extract and their Antibacterial Activities. Energy Procedia 2016, 89, 239-247. [CrossRef]

(C) 2020 by the authors. Licensee MDPI, Basel, Switzerland. This article is an open access article distributed under the terms and conditions of the Creative Commons Attribution (CC BY) license (http://creativecommons.org/licenses/by/4.0/). 